\title{
PERSPECTIVE
}

\section{The origins of bladder cancer}

\author{
James M Crawford
}

Bladder cancer, arising from the transitional cells of the mucosal urothelium, may present as a noninvasive, papillary tumor protruding from the mucosal surface, or as a solid, nonpapillary tumor that invades the bladder wall and has a high propensity for metastasis. The nonpapillary tumors originate from in situ dysplasia. The most common environmental risk for bladder cancer is active smoking; occupational exposure to arsenic or other carcinogens is also a risk factor. A possible familial component to bladder cancer has been described. Conventional models of carcinogenesis suppose the existence of successive mutation events within a specific cell clone, enabling its eventual escape from regulation of cell division and maintenance of genomic integrity. Important new information has emerged from whole-organ mapping of the mucosal genome in bladders resected for invasive cancer (Majewski et al, Lab Invest; published online 5 May 2008). Mapping of genetic hits across the entire mucosa demonstrates genetic alterations in six chromosomal regions, not only in mucosal regions of evident dysplasia, but also in morphologically normal mucosa. These clonally expanded regions cover vast expanses of the bladder surface, as a 'first wave' of pre-neoplasia. Target genes in these regions are termed 'forerunner genes' (FR genes), based on the concept that these genes enable the initial clonal expansion of in situ urothelial neoplasia. Extensive further analysis of human populations with urothelial cancer implicates genetic polymorphisms in one of these genes, $P 2 R Y 5$, as being present in a familial cluster of cancers of multiple organs, and as imparting risk for development of bladder cancer in active smokers. $P 2 R Y 5$ is a gene encoded within intron 17 of $R B 1$, a prototypic tumor suppressor gene whose expression is lost at a later stage of bladder carcinogenesis. Alterations of the FR gene status provide a novel opportunity to screen individuals at risk for the earliest stage of bladder pre-neoplasia and represent attractive targets for therapeutic and chemopreventive interventions. These findings support the hypothesis that bladder carcinogenesis is initiated by clonal expansion of genetically altered but histologically normal cells that cover broad expanses of the mucosa. Effort must now be given to identifying the biological function of these novel FR genes. Laboratory Investigation (2008) 88, 686-693; doi:10.1038/labinvest.2008.48; published online 12 May 2008

KEYWORDS: bladder cancer; forerunner genes; P2RY5; RB1; whole-organ mapping; genomic mapping

\section{EPIDEMIOLOGY OF BLADDER CANCER}

Bladder cancer is the fourth most incident cancer in males and ninth most incident in females. In the United States, over 67000 new cases are diagnosed per year, ${ }^{1}$ and over 350000 cases diagnosed worldwide. ${ }^{2}$ In the United States, the annual age-adjusted incidence rate for men is approximately 32 per $100000 .^{3}$ Men have a higher risk of bladder cancer than women, by a rate ratio of at least 3:1. Approximately $66 \%$ of bladder cancers are diagnosed among individuals age 65 years or older.

Bladder cancer arises primarily from the transitional cells of the bladder mucosal epithelium (90\% of cases) and may present as a noninvasive, papillary tumor protruding from the mucosal surface that is readily resectable. Although these superficial tumors frequently recur after cystoscopic resec- tion, they usually do not invade the bladder wall or metastasize. However, about one-third of incident bladder cancers present as solid, nonpapillary tumors, which originate from in situ dysplasia and carcinoma in situ. These tumors invade the bladder wall and have a high propensity for metastasis. ${ }^{4-6}$ For these invasive tumors, 5-year survival rate is only $30-50 \% .^{7,8}$ This stark difference in morphology and survival implicates separate oncogenic pathways for noninvasive $v s$ muscle-invasive cancer. ${ }^{9}$

The incidence of bladder cancer was strongly associated with occupational exposure to aromatic amines used in the dye industry, before their potent carcinogenicity to the bladder was demonstrated. ${ }^{10}$ With reduction of such workplace exposure, active smoking is now the strongest environmental risk for bladder cancer, contributing to more

Department of Pathology, Immunology and Laboratory Medicine, University of Florida College of Medicine, Gainesville, FL, USA

Correspondence: Dr JM Crawford, MD, PhD, Department of Pathology, Immunology and Laboratory Medicine, University of Florida College of Medicine, PO Box 100275, Gainesville, FL 32610-0275, USA.

E-mail: crawford@pathology.ufl.edu

Received 23 April 2008; accepted 23 April 2008 
than $50 \%$ of cases. $^{2}$ Recent modest reductions in the incidence of bladder cancer are attributed to decreasing exposure to tobacco smoking and to occupational carcinogens. Although diet might also influence bladder carcinogenesis, owing to the many potential carcinogens or chemopreventive nutrients therein, ${ }^{11}$ no consistent association between intake of selected nutrients or micronutrients and bladder cancer has emerged. Other lifestyle habits have been widely investigated, such as intake of coffee, artificial sweeteners, hair dyes, and have not been materially associated with bladder cancer. ${ }^{2}$ Any contribution from the chronic irritation of the bladder mucosa from recurrent urinary tract infections or stones is modest. ${ }^{12,13}$ Hence, at this time, the primary environmental risk for bladder cancer is smoking. Active smoking and longer smoking duration are associated with increased risk for bladder cancer, when compared with neveror former-smokers. ${ }^{14-16}$ Smoking intensity (cigarettes smoked per day or pack-years smoked) is not a separate independent risk variable. ${ }^{17}$

\section{BLADDER CANCER CARCINOGENESIS}

In the most general sense, conventional models of carcinogenesis suppose the existence of successive mutation events within a specific cell clone, enabling its eventual escape from regulatory mechanisms for cell division and maintenance of genomic integrity. ${ }^{10}$ Environmental carcinogens are thought to interact with the genome at an early stage, for example, by forming DNA adducts that induce DNA mutation at their binding sites. Exposure to carcinogens at later stages of carcinogenesis may involve completion of previous carcinogenetic steps. Both time lines appear to be operative in the effect of smoking on tissues of the lung, bladder, and upper digestive tract.

Aromatic polycyclic hydrocarbons, nitrosamines, and aromatic amines generated by smoking have well-established carcinogenic influence. Smoking imparts risk for destabilization of cell-cycle control pathways and susceptibility to bladder cancer. ${ }^{18}$ However, the human population exhibits extraordinary variability in susceptibility to the risk of smoking. The chief genetic polymorphisms studied to date are xenobiotic-metabolizing enzymes. ${ }^{19}$ Polymorphisms in the enzymes CYP1A1 and GSTM1 contribute to the host ability to detoxify these carcinogens, and hence host susceptibility to their carcinogenic influence. To date, however, genetic predispositions in susceptibility to the direct carcinogenic effect of smoking in bladder carcinogenesis have not been elucidated.

A more fruitful area of investigation for bladder carcinogenesis has been evaluating the molecular basis for aggressive bladder cancer. Particular focus has been given to epigenetic alteration, ${ }^{20}$ with DNA hypermethylation and inactivation of tumor suppressor genes leading to poor patient survival. ${ }^{21-23}$ Epigenetic gene methylation has been linked to exposure to tobacco smoke and exposure to drinking water arsenic. $^{24}$ Promoter hypermethylation may affect an in- creasing number of genes with increasing disease stage in bladder cancer. $^{21,25,26}$

In patients with bladder cancer, increasing age, male gender, and current cigarette smoking are positively identified with a methylation trait. ${ }^{17}$ Occult DNA promoter hypermethylation as a latent trait can drive a methylator phenotype. $^{27}$ Analysis of cumulative epigenetic events permits assessment of the underlying propensity for promoter hypermethylation. $^{28}$ Both smoking and inorganic arsenic exposure are associated with gene-specific promoter hypermethylation in bladder cancer. $^{21,25}$ The genetic polymorphisms and sites of hypermethylation are numerous, involving genes that span the range of cellular processes, including intracellular regulatory networks driving development growth. ${ }^{17}$ Accumulation of hypermethylation events may be related to the aging process and increased duration of carcinogen exposure, with increased DNA damage and genomic instability. Epigenetic predictive models using artificial intelligence also support the premise that promoter hypermethylation is a reliable predictor of tumor progression in bladder cancer. ${ }^{29}$ Collectively, these data support the concept that cigarette smoke is not only a direct mutagenic carcinogen, but also associated with the genesis of epigenetic alterations in bladder cancer. ${ }^{30}$ Continuous tobacco carcinogen exposure, in combination with increasing age and male gender, drives and enhances the selection and clonal expansion of epigenetically altered cells. ${ }^{17}$

Previously published clinical reports have indicated a possible familial component to bladder cancer. ${ }^{31-34}$ There is a significantly increased risk of bladder cancer among firstdegree relatives of individuals who have bladder cancer, with an earlier age of disease onset. ${ }^{35-37}$ In a large twin study, environmental factors were estimated to contribute a significant $69 \%$ to bladder cancer risk, whereas inherited genetic factors contributed a nonsignificant $31 \%$ of risk. ${ }^{38}$ Attention has been given to the NAT2 slow acetylator and GSTM1-null genotypes as potential familial risk factors. ${ }^{39}$ Such data support the concept of low-penetrance cancer-predisposing polymorphisms acting together and/or interacting with environmental factors, to increase the familial risk of bladder cancer. $^{40}$

However, the familial risk of bladder cancer is not well understood and, to date, little attention has been paid to the joint effect of smoking and family history in modifying the risk of bladder cancer, in part because of the limitations of case control studies. This limitation was overcome in a family-based population analysis of incident bladder cancer, in which probands who had smoked and who also had a positive family history were at 5.31-fold increased risk of bladder cancer. ${ }^{41}$ For never-smoking individuals with bladder cancer, the disease was diagnosed at a later age ( $>65$ years) than smokers, in which the cancer presented at ages 40-65 years. Smoking imparted a 6.89-fold increased risk (95\% confidence interval 2.25-fold to 21.21-fold). This study indicated that a positive family history of bladder cancer 
interacted with smoking habits to increase the risk of bladder cancer; the $P$-value for the interaction of smoking and family history was $P=0.04$. Stated differently, a family history of bladder cancer confers increased risk only among active smokers.

The chief questions pertaining to the pathogenesis of bladder cancer are summarized in Table 1 . It is against this backdrop that a most remarkable study of bladder carcinogenesis has been conducted, which provides substantive new insights into the first five questions.

\section{Table 1 Chief questions pertaining to the pathogenesis of bladder cancer}

What are the earliest molecular events in bladder carcinogenesis?

What determines host susceptibility to environmental carcinogens, especially smoking?

Are there molecular determinants for familial risk of bladder cancer?

What role do epigenetic events play in bladder carcinogenesis?

What are the molecular determinants of aggressive (invasive) bladder cancer?

What is the basis for the gender differences in bladder cancer incidence?

\section{WHOLE-ORGAN MAPPING OF THE BLADDER CANCER GENOME}

A bold new approach has now been taken to examine bladder carcinogenesis. Using a whole-organ mapping strategy, Czerniak and coworkers ${ }^{42-44}$ have previously examined genetic hits across the entire mucosa of bladders affected by cancer. Their construction of a genome-wide map over the entire mucosa has enabled identification not only of genetic alterations in mucosal regions of evident dysplasia, but also in morphologically normal mucosa. Rectangular tissue samples, $1 \times 2 \mathrm{~cm}$ in size, were obtained from the entirety of resected human bladders with invasive cancer and analyzed for morphological features of cancer or its precursor lesions, and at the molecular level. The comprehensive completion of this extraordinary body of work is presented in this current issue of Laboratory Investigation, as summarized in Box $1 .^{45}$

The fundamental concept is that critical regions of chromosomes, both for noncoding DNA sequences and for novel genes, may be involved in the earliest phases of cancer development. Based on this work with bladder cancer, Czerniak and coworkers term the target genes they have identified in the key six chromosomal regions as 'forerunner genes' (FR genes). This is based on the concept that these genes are relevant for the development of the initial clonal expansion of in situ urothelial neoplasia. ${ }^{44}$

Box 1 Whole-organ mapping of the bladder cancer genome ${ }^{45}$

- Selection of DNA markers for initial evaluation of mucosal tissue samples was based on screening paired nontumor DNA (peripheral blood) and DNA from invasive tumor. Markers showing loss of heterozygosity $(\mathrm{LOH})$ were then used to screen the entire set of whole-organ tissue samples from five bladders focally affected by invasive bladder cancer.

- The pattern of $\mathrm{LOH}$ of chromosomes 1-22 was then used to construct a genome-wide map and geographic map of chromosomal instability. Six chromosomal regions critical for clonal expansion of in situ neoplasia were identified, at 3q22-q24, 5q22-q31, 9q21-q22, 10q26, 13q14, and 17p13. $\mathrm{LOH}$ at these sites in any one bladder was persistent through the entire sequence of bladder neoplasia, from morphologically normal regions of mucosa to invasive carcinoma.

- In the original cystectomy specimens, all areas of bladder mucosa with LOH were geographically related. Even those markers that exhibited allelic loss across several separate areas of mucosa were related, and represented successive subclones emerging from a larger clonal field change, as defined by nearest-neighbor analysis.

- Validation of the relevance of these six chromosomal regions to the bladder cancer was obtained by testing paired samples of voided urinary DNA and peripheral blood DNA from 63 patients with documented bladder cancer. LOH affecting at least one of these critical chromosomal regions could be identified in $98 \%$ of the voided urine samples.

- High-resolution whole-organ genomic mapping of the original five bladders was then performed for one of the six critical chromosomal regions, using high-density SNPs that spanned the $26.9 \mathrm{Mb}$ around a model tumor suppressor gene, $R B 1$, on chromosome $13 q 14$. This gene is a prototypic tumor suppressor gene, originally identified in a familial form of retinoblastoma and a key gene implicated in urothelial carcinogenesis. In this study, a $1.34 \mathrm{Mb}$ minimal deleted region flanking RB1 was identified, containing several positional genes, which appear to be involved in the clonal expansion of in situ neoplasia.

- Of the 11 positional candidate genes, two genes flanking $R B 1$ were studied further, namely ITM2B and $R C B T B 2$. A third gene was of particular interest, $P 2 R Y 5$, because it is a complete gene located within intron 17 of $R B 1$. Clonal loss of these three genes could be identified in morphologically normal bladder mucosa, across broad swaths of the bladder surface.

- The clonal loss of these three target genes was then verified on 111 paired samples of bladder cancer DNA vs peripheral blood DNA, from a further set of human patients. Loss of DNA polymorphism (LOP) involving the $3.16 \mathrm{Mb}$ of chromosome 13 flanking $R B 1$ could be detected in $55 \%$ of the 111 bladder cancer samples. In 28\% of these cases, it contiguously involved RB1 and its flanking regions. In an additional 19\% of all tumor samples, LOP was restricted to regions flanking $R B 1$. 
Three waves of genetic 'hits' in the bladder mucosa were identified. The first wave constituted clonal expansion of phenotypically normal-appearing urothelial cells over large portions of the bladder mucosa. The second wave was associated with subregions of clonally expanded cells showing the first microscopically recognizable features of dysplasia. The third and last wave was associated with the fully transformed phenotype of severe dysplasia/carcinoma in situ. Notably, further advancement to invasive cancer was not associated with additional major loss of genetic material. During the first wave, loss of a genomic region around $R B 1$ in one chromosome was not uniformly associated with inactivation of the second $R B 1$ allele. Inactivation of the second allele, as by point mutation, with ultimate inactivation of the $R B 1$ gene, was a later event corresponding to the third wave. Hence, loss of FR genes in the region of $R B 1$ provide the initial growth advangage during the first wave, to enable expansion of a clonal geographic region of morphologically normal urothelial epithelium. Subsequent loss of a tumor suppressor gene, such as $R B 1$, was a transforming event, associated with development of high-grade dysplasia/carcinoma in situ, progessing to invasive cancer.

These data also provide evidence that a limited number of critical steps, in this case at least six, are required for tumorigenesis of invasive bladder cancer. Although the constellation of genomic-wide hits is highly variable, they ultimately act in concert.

\section{ALTERATIONS IN FORERUNNER GENES IN PATIENTS WITH BLADDER CANCER}

The DNA sequences, expression patterns, and methylation status of RB1 and candidate FR genes in the $13 \mathrm{q} 14$ chromosomal region around $R B 1$ were then analyzed, as summarized in Box $2 .{ }^{44,45}$ The detailed analysis of P2RY5 polymorphisms, including germ-line mutations, provides remarkable data in support of potential inherited host susceptibility to the carcinogenic effects of smoking. Mapping of the P2RY5 polymorphisms in normal bladder mucosa demonstrated that this gene, which resides within intron 17 of the $R B 1$ gene, is affected before loss of $\mathrm{RB}$ expression during bladder carcinogenesis. Third, pedigree analysis revealed one family with an inherited risk of cancer, which carried a germline mutation in P2RY5. In addition, the expression pattern of several additional candidate FR genes indicates that GPR38, CAB39L, RCBTB1, and ARL11 had more than 50\% reduction of their expression in several bladder cancer cell lines and should be further investigated as potential candidate FR genes. Lastly, downregulation of FR genes was identified in $2 / 3$ of a series of cancer cell lines from a variety of other human malignancies.

The body of work presented by Majewski et al ${ }^{45}$ constitutes an extraordinarily comprehensive exploration of bladder carcinogenesis in specific and principles of carcinogenesis in general. The data provide substantive new insight into the following: familial risk of bladder cancer; host susceptibility to the effects of smoking; and molecular changes in FR genes,

\section{Box 2 Forerunner gene sequencing and polymorphisms ${ }^{44,45}$}

- Forerunner gene expression and methylation status were examined on paired samples of normal adjacent urothelium and tumor, from a separate set of 195 patients with bladder cancer (transitional cell carcinoma, TCC). This included large-scale molecular testing of two FR genes, which demonstrated that one was affected by methylation (ITM2B), and the other by mutations (P2RY5). Hypermethylation of ITM2B was found in $40 \%$ of bladder tumors. Missense point mutations in P2RY5 were found in 7\% of TCCs, some of which were germ-line alterations.

- One of the polymorphic sites in P2RY5 (G1722T) results in substitution of cysteine for tryptophan at position 307; this polymorphism was detected in bladder tumor DNA and nontumor DNA in several patients. The G1722T mutation affects the interaction of the P2RY5 protein with the G-protein complex, which would compromise its biological activity.

- Loss of the wild-type $1722 \mathrm{G}$ P2RY5 allele and retention of variant $1722 \mathrm{~T}$ P2RY5 occurred in the in situ phase of bladder neoplasia, and preceded loss of RB protein expression.

- Analysis of peripheral blood DNA from 790 patients with bladder cancer and 712 age- and sex-matched controls revealed the somatic 1722 G-T polymorphism of P2RY5 in 22 (2.78\%) of bladder cancer patients and 20 (2.81\%) of controls. There were no individuals with a homozygous 1722 T-T genotype. The presence of the 1722 G-T genotype did not itself impart a higher risk for bladder cancer. However, all five individuals with the 1722 G-T genotype who were active smokers had developed bladder cancer.

- Sequencing analysis of index bladder cancer cases from 46 families with high incidences of various common malignancies was performed. Germ-line mutation of $P 2 R Y 5$ was identified in one of these families, in the midst of an otherwise wild-type $R B 1$ gene (remember that $P 2 R Y 5$ is encoded entirely within intron 17 of RB1). The cancers in this family included breast, colon, lung, prostate, and uterus. Tumors of affected family members had wild-type alleles of $p 53$ and $B R C A 1 / 2$, but the germ-line mutation of P2RY5 in one allele combined with acquired loss of the wild-type allele in the tumors.

- To further explore whether loss of FR gene function is a frequent phenomenon in human carcinogenesis, the sequence, methylation status, and expression of RB1 and selected candidate FR genes were tested in 62 cell lines derived from a variety of human malignancies (lung, breast, colorectal, liver, prostate, hematopoietic, pediatric). At least one of the FR genes was downregulated in $63 \%$ of the 62 cell lines, and typically more than one FR gene was downregulated. 
which precede both morphological changes in the bladder mucosa and genetic/epigenetic alterations in more conventional tumor suppressor genes. The clonal expansion, over vast expanses of the bladder mucosa, of urothelial cell populations containing losses of FR genes may represent the earliest molecular change in bladder carcinogenesis. At the least, these genetic alterations are earlier than previously reported preneoplastic changes. In the case of chromosome 13, the fact that the FR genes are in the immediate vicinity of the known oncogene $R B 1$, and that their loss precedes loss of $R B 1$ function, significantly revises the concept of chromosomal regions of susceptibility. Lastly, initial evidence is given that losses of genetic material in the FR gene-containing regions can be detected in exfoliated urine DNA from virtually all patients with bladder cancer, thereby constituting a potential diagnostic tool for detecting bladder cancer at its earliest stages.

\section{THE CONTEXT OF CURRENT LITERATURE}

In identifying genomic imbalances, it is difficult to discern which imbalances are primary causal events and which are redundant hits dragged through clonal progression simply by cosegregation. Although analysis of families with a high frequency of cancer can help to identify genomic regions of interest, the vast majority of human cancers are sporadic in nature and are thus not amenable to family analysis. The alternative strategy of identifying the geographic distributions of genes, in human tissue containing cancer, has been used to advantage in cancers such as colorectal and esophageal cancers. ${ }^{46,47}$ Identification of clonal plaque-like regions is of interest, regardless of whether morphological features of pre-neoplasia (dysplasia) are evident. Indeed, clonal expansion of normal mucosal tissue is of immense interest and underpins the concept of 'forerunner genes'. At the opposite end of the genomic spectrum are hits restricted to regions of severe dysplasia or carcinoma in situ, which represent late events associated with progression to invasive cancer. The current study by Majewski et $a l^{45}$ spans the entirety of both geographic and familial cosegregation analyses.

These findings are central to the hypothesis that bladder carcinogenesis is initiated by genetically altered but histologically normal cells that produce fields of altered cells by intraepithelial displacement. ${ }^{48}$ Upon accumulation of further genetic changes, the fields of altered urothelium reach a state of criticality and there is production of frank tumors. The current work extends the published data set from conventional metaphase comparative genomic hybridization, which has detected recurrent gain and amplification at 6 p22 in up to $31 \%$ of bladder tumors and bladder cancer cell lines. ${ }^{49,50}$

The work of Majewski et al, ${ }^{45}$ and that of the preceding papers from this same group, ${ }^{42-44}$ also puts further emphasis on the role of the chromosomal region containing RB1. Invasive urothelial cancers are characterized by severe disturbances in proximate cell-cycle regulators, of which $R B 1$ is key. ${ }^{51}$ These disturbances are exacerbated by chromosomal instability and, in turn, permit and promote such instability. This leads to concomitant and interacting defects in cell-cycle regulation and the control of genomic stability, enabling the transition toward invasive cancer. In a previous study relevant to the $R B 1$ story, a $2.5 \mathrm{Mb}$ region of $6 \mathrm{p} 22$ was found to play a role in bladder carcinogenesis. ${ }^{52}$ Specifically, among the several genes in this region, E2F3 belongs to the E2F family of transcription factors, and encodes two protein products (E2F3a and E2F3b) through the use of alternative promoters and different $5^{\prime}$-coding exons. ${ }^{53}$ E2F3a is a transcriptional activator, is expressed in proliferating cells, reaching peak levels in late G1, and is linked to transactivation of genes associated with DNA synthesis and cell-cycle progression. ${ }^{53,54}$ Notable from the current study of Majewski et $a l^{45}$ is the fact that activation of E2F3a target genes is repressed during G1 when E2F3a is bound to the retinoblastoma protein, RB. ${ }^{55}$ During G1/S, RB becomes hyperphosphorylated, leading to the release of E2F3a and subsequent target gene activation. ${ }^{56}$ E2F3a is the predominant binding partner for RB in G0. Overexpression of E2F3 and a second gene from the $6 \mathrm{p} 22$ region, CKDAL1, has been documented in bladder tumor tissue microarrays ${ }^{57}$ and in bladder cancer cell lines. ${ }^{58}$ Hurst $^{59}$ has recently demonstrated that there is a functional link between E2F3 overexpression and proliferative advantage in bladder tumor cells with 6p22 amplification; knockdown of CDKAL1 had no effect on cell proliferation. Amplification of 6 p22.3 was identified in 8 out of 91 invasive bladder tumors. In five tumors studied in detail, four showed 13q14.2 loss (including RB1) and expressed no RB protein. The fifth had an alternative mechanism for RB inactivation, through hyperphosphorylation. These authors conclude that inactivation of the $\mathrm{RB}$ pathway is required in addition to E2F3 overexpression in this subset of bladder tumors.

Analysis of the methylation status of $\mathrm{CpG}$ islands in the promoter regions of genes associated with primary papillary bladder cancer (GSTP1, DAPK, MDR1, TPEF, PAX6, and TSLC1) has been performed. ${ }^{60}$ Only TPEF and PAX6 had substantial $\mathrm{CpG}$ island methylation percentages, which were higher in tumor tissue when compared with normal mucosa adjacent to the tumor. However, even normal mucosa had elevated levels of TPEF and PAX6 hypermethylation, thereby possibly representing biomarkers for this form of bladder cancer. The latter study also points out the potential differences in molecular carcinogenesis between papillary and nonpapillary bladder cancer. However, it is remarkable that losses of genetic material in six chromosomal regions are relevant to both papillary and nonpapillary cancer as well.

Such genome-wide screening methodologies will no doubt be of value for other cancers. Over-and-above documented differences between papillary and nonpapillary bladder cancer, current data make clear that different genetic regions are likely to be operative in different tissue sites. ${ }^{61-68}$ 


\section{IMPLICATIONS FOR THE DETECTION AND PREVENTION OF BLADDER CANCER}

In keeping with the most fundamental tenets of cancer care, early detection of bladder cancer is considered to improve patient prognosis and decrease the need for cystectomy, by identifying tumors before they become muscle invasive. Current detection methods involve the use of cystoscopy, radiographic imaging, and urine cytology. Because this detection paradigm is among the most expensive of cancer detection protocols for various human tissues, an intense search is underway to identify effective-and inexpensivebiomarkers of early bladder cancer. ${ }^{69}$ The ideal bladder tumor biomarker would be noninvasive, easy to use, reliable, and efficacious. ${ }^{70}$ Current urinary biomarkers under evaluation for detection of occult bladder cancer are given in Table 2.

Recent clinical reports include urine screening of individuals with $\geq 40$ pack-years of smoking, using combined UroVysion, cytology, and urinary dipstick testing for hematuria, which found malignancy in 3.3\% of these high-risk individuals. ${ }^{71}$ Likewise, microsatellite analysis of exfoliated urine to detect DNA $\mathrm{LOH}$, combined with performance of UroVysion FISH and conventional urine cytology, enabled detection of over $93 \%$ of patients with recurrent bladder cancer. ${ }^{72}$ Analysis of urine for microsatellite alterations shows a high correlation with invasive tumor resident within the bladder $^{73}$ and exhibits high sensitivity for patients who have invasive cancer. ${ }^{74}$

Surprisingly, the most important biomarker of bladder cancer is microscopic or gross hematuria, which occurs in $85 \%$ of patients with bladder cancer. ${ }^{75}$ Repeat home urine dipstick testing followed by medical evaluation of positive patients may achieve $90-95 \%$ sensitivity. ${ }^{76}$ With the home hematuria testing protocol, newly diagnosed patients with bladder cancer had muscle invasion in only $10 \%$ of cases, as opposed to $60 \%$ in newly diagnosed bladder cancer patients who had not been screened for hematuria. ${ }^{76}$ This translated into lower disease-specific and overall mortality than unscreened patients. Unfortunately, the positive-predictive value of hematuria is only $0.08 \% .{ }^{77}$ Hence, there is desperate need to stratify hematuria-positive patients into low- and high-risk groups.

As discussed earlier, smoking is the most frequent risk factor associated with bladder cancer and is estimated to account for up to $50 \%$ of bladder cancers in men. ${ }^{78}$ Stopping smoking and avoiding exposure to second-hand smoke should be an effective method of decreasing the incidence of this disease. Such a strategy is an example of primary chemoprevention, namely preventing occurrence of disease in a healthy population. A prospective study to demonstrate this effect would be both expensive and time consuming because of the long lag between exposure to carcinogens and the development of bladder cancer. ${ }^{79}$ So-called 'secondary prevention' treats people with well-defined premalignant conditions to prevent the development of clinical cancer. As such premalignant disease states have not been generally recognized in bladder cancer, this approach has not been used in this disease.

The FR genes represent novel biomarkers for detection of the premalignant state and of outright cancer and also represent targets for therapeutic and preventive interventions. Examining urinary DNA for alterations in FR gene status

Table 2 Current biomarkers for bladder cancer (Alvarez, 2007)

\begin{tabular}{|c|c|}
\hline BTA-Stat/TRAK & Complement factor $\mathrm{H}$ and complement factor $\mathrm{H}$-related protein \\
\hline NMP22 & Nuclear matrix proteins \\
\hline Hyaluronic acid/hyaluronidase & Molecular determinants of bladder tumor growth, invasion, angiogenesis \\
\hline Survivin & Antiapoptotic protein associated with aggressive cancer behavior \\
\hline Telomerase & Regenerates DNA telomeres, imparts cell immortality \\
\hline $\mathrm{FISH}$ & $\begin{array}{l}\text { Fluorescence in-situ hybridization for aneuploidy of chromosomes 3, 7, 17, and loss of locus } 9 \text { p21 } \\
\text { (= UryoVysion-Abbott Laboratories, Des Plaines, IL) }\end{array}$ \\
\hline Microsatellite DNA analysis & PCR analysis of exfoliated cell DNA in urine to detect mutations/LOH \\
\hline DNA methylation & Aberrant methylation or hypermethylation of promoters leads to silencing of tumor suppressor genes \\
\hline BCLA-4 & $\begin{array}{l}\text { Nuclear matrix protein in the ETS transcription factor family, expressed in normal urothelium of patients with } \\
\text { bladder cancer, but not in urothelium of people without bladder cancer }\end{array}$ \\
\hline Cytokeratins & Detection of cytokeratin-8, $-18,-19$ in urine \\
\hline ImmunoCyt/uCyt+ & Immunofluorescence to detect sulfated mucin glycoproteins and carcinoembryonic antigen \\
\hline Soluble Fas & Expression of sFas by cancer cells inhibits apoptosis; urinary detection of sFas \\
\hline Proteomics & Disease-specific polypeptide patterns - urine and serum \\
\hline Genomics & $\begin{array}{l}\text { Gene profiling of molecular signatures; for example, human chorionic gonadotropin } \beta \text {-subtype; urothelial } \\
\text { carcinoma-associated } 1 \text { gene }\end{array}$ \\
\hline
\end{tabular}


might identify bladders at risk for urothelial neoplasia long before the preneoplastic pathway actually begins. Clinical monitoring and therapeutic management protocols, including recommendations about smoking, are readily envisaged.

Tertiary prevention, preventing recurrences in patients with a history of cancer who are currently clinically free of disease, is the approach that has been generally used to investigate chemoprevention of bladder cancer. Several randomized clinical trials have been completed, evaluating a variety of agents including high-dose vitamins, retinoids, and difluoromethylornithine for the chemoprevention of bladder cancer. ${ }^{80-86}$ These studies, although generally disappointing, have shown that drugs used for chemoprevention must have low toxicity and that study design may be critical to success. ${ }^{87}$ Again, monitoring of such patients on the basis of FR gene status is an attractive possibility.

One final comment pertains. Identification of FR genes creates extraordinary opportunity to examine the molecular biology of these novel modulators of cancer risk. It is not yet clear how many coding genes are present in the six chromosomal regions of interest. For those FR genes currently identified (eg, P2RY5), it is now imperative that their function be elucidated in the context of carcinogenesis.

1. Jemal A, Siegel R, Ward E, et al. Cancer statistics 2007. CA Cancer J Clin 2007:57:43-66.

2. Ferlay J, Randi G, Bosetti $C$, et al. Declining mortality from bladder cancer in Europe. Br J Urol 2007;101:11-19.

3. Jemal A, Murray T, Ward E, et al. Cancer statistics 2005. CA Cancer J Clin 2005:55:10-30.

4. Knowles MA. The genetics of transitional cell carcinoma: progress and potential clinical application. Brit J Urol Int 1999;84:412-427.

5. Speiss PE, Czerniak B. Dual-track pathway of bladder carcinogenesis: practical implications. Arch Pathol Lab Med 2006;130:844-852.

6. Malkowicz SB, Van Poppel H, Mickisch G, et al. Muscle-invasive urothelial carcinoma of the bladder. Urology 2007;69(Suppl 1): 3-16.

7. Stein JP, Skinner DG. Radical cystectomy for invasive bladder cancer: long-term results of a standard procedure. World J Urol 2006;24: 296-304.

8. Hermann GG, Horn T, Steven K, et al. The influence of the level of lamina propria invasion and the prevalence of p53 nuclear accumulation on survival in stage $\mathrm{T} 1$ transitional cell bladder cancer. J Urol 1998;159:91-94.

9. Dinney CP, McConkey DJ, Millikan RE, et al. Focus on bladder cancer. Cancer Cell 2004;6:111-116.

10. Clavel J. Progress in the epidemiological understanding of geneenvironment interactions in major diseases: cancer. C R Biol 2007;330:306-317.

11. Tang L, Zirpoli GR, Guru K, et al. Consumption of raw cruciferous vegetables is inversely associated with bladder cancer risk. Cancer Epidemiol Biomarkers Prev 2008;17:938-944.

12. Pelucchi C, Bosetti C, Negri E, et al. Mechanisms of disease: the epidemiology of bladder cancer. Nat Clin Pract Urol 2006;3:327-340.

13. Silverman DT, Devesa SS, Moore LE, et al. Bladder cancer. In: Schottenfeld D, Fraumeni JF (eds). Cancer Epidemiol Prev. Oxford University Press: Oxford, 2006, pp 1101-1127.

14. Jee $\mathrm{SH}$, Samet JM, Ohrr H, et al. Smoking and cancer risk in Korean men and women. Cancer Causes Control 2004;15:341-348.

15. Gritz ER, Dresler C, Sarna L, et al. Smoking, the missing drug interaction in clinical trials: ignoring the obvious. Cancer Epidemiol Biomarkers Prev 2005;14:2287-2293.
16. Zeegers MP, Goldbohm RA, van den Brandt PA. A prospective study on active and environmental tobacco smoking and bladder cancer risk (The Netherlands). Cancer Causes Control 2002;13:83-90.

17. Marsit CJ, Houseman EA, Schned AR, et al. Promoter hypermethylation is associated with current smoking, age, gender and survival in bladder cancer. Carcinogenesis 2007;28:1745-1751.

18. Ye $\mathrm{Y}$, Yang $\mathrm{H}$, Grossman HB, et al. Genetic variants in cell cycle control pathway confer susceptibility to bladder cancer. Cancer, published online 24 March 2008, PMID 18361427.

19. Gaspari L, Marinelli D, Taioli E, Collaborative Group on Genetic Susceptibility to Environmental Carcinogens. Int J Hyg Environ Health 2001;204:39-42.

20. Jones PA, Gonzalgo ML, Tsutsumi M, et al. DNA methylation in bladder cancer. Eur Urol 1998;33(Suppl 4):7-8.

21. Marsit CJ, Karagas MR, Andrew A, et al. Epigenetic inactivation of SFRP genes and TP53 alteration act jointly as markers of invasive bladder cancer. Cancer Res 2005;65:7081-7085.

22. Maruyama R, Toyooka S, Toyooka KO, et al. Aberrant promoter methylation profile of bladder cancer and its relationship to clinicopathological features. Cancer Res 2001;612:8659-8663.

23. Stoehr R, Wissmann C, Suzuki H, et al. Deletions of chromosome $8 p$ and loss of sFRP1 expression are progression markers of papillary bladder cancer. Lab Invest 2004;84:465-478.

24. Marsit CJ, Karagas MR, Danaee $\mathrm{H}$, et al. Carcinogen exposure and gene promoter hypermethylation in bladder cancer. Carcinogenesis 2006;27:112-116.

25. Salem C, Liang G, Tsai YC, et al. Progressive increases in de novo methylation of $\mathrm{CpG}$ islands in bladder cancer. Cancer Res 2000;60:2473-2476.

26. Marsit CJ, Houseman EA, Christensen BC, et al. Examination of a CpG island methylator phenotype and implications of methylation profiles in solid tumors. Cancer Res 2006;66:10621-10629.

27. Sanchez B, Budtz-Jørgensen E, Ryan LM, et al. Structural equation models - a review with applications to environmental epidemiology. J Am Stat Assoc 2005;1000:1443-1455.

28. Bartholomew DJ. Latent Variable Models and Factor Analysis. Oxford University Press: New York, 1999.

29. Yates DR, Rehman I, Abbod MF, et al. Promoter hypermethylation identifies progression risk in bladder cancer. Clin Cancer Res 2007;13:2046-2053.

30. Belinsky SA. Silencing of genes by promoter hypermethylation: key event in rodent and human lung cancer. Carcinogenesis 2005;26: 1481-1487.

31. Lynch $\mathrm{H}$, Walzak $\mathrm{M}$, Fried $\mathrm{R}$, et al. Familial factors in bladder carcinoma. J Urol 1979;122:458-461.

32. Fraumeni Jr JF, Thomas LB. Malignant bladder tumors in a man and his three sons. J Am Med Assoc 1967;201:97-99.

33. Mahboubi A, Ahlvin R, Mahboubi E. Familial aggregation of urothelial carcinoma. J Urol 1981;126:691-692.

34. McCullough DL, Lama DL, McLaughlin AP, et al. Familial transitional cell carcinoma of the bladder. J Urol 1975;113:629-635.

35. Kramer A, Graham S, Burnett W, et al. Familial aggregation of bladder cancer stratified by smoking status. Epidemiology 1991;2: $145-148$.

36. Aben $\mathrm{KKH}$, Witjes JA, Schoenberg MP, et al. Familial aggregation of urothelial cell carcinoma. In J Cancer 2002;98:274-278.

37. Randi G, Pelucchi C, Negri E, et al. Family history of urogenital cancers in patients with bladder, renal cell and prostate cancers. Int J Cancer 2007;121:2748-2752.

38. Lichtenstein R, Holm NV, Verkasalo PK, et al. Environmental and heritable factors in the causation of cancer. Analyses of cohorts of twins from Sweden, Denmark, and Finland. N Eng J Med 2000;343: 78-85.

39. Murta-Nascimento C, Schmitz-Dräger BJ, Zeegers MP, et al. Epidemiology of urinary bladder cancer: from tumor development to patient's death. World J Urol 2007;25:285-295.

40. Murta-Nascimento C, Silverman DT, Kogevinas M, et al. Risk of bladder cancer associated with family history of cancer: do low-penetrance polymorphisms account for the increase in risk? Cancer Epidemiol Biomarkers Prev 2007;16:1595-1600.

41. Lin J, Spitz MR, Dinney CP, et al. Bladder cancer risk as modified by family history and smoking. Cancer 2006;107:705-711. 
42. Tuziak T, Jeong J, Majewski T, et al. High-resolution whole-organ mapping with SNPs and its significance to early events of carcinogenesis. Lab Invest 2005;85:689-701.

43. Kim MS, Jeong J, Majewski T, et al. Evidence for alternative candidate genes near RB1 involved in clonal expansion of in situ urothelial neoplasia. Lab Invest 2006;86:175-190.

44. Lee S, Jeong J, Majewski T, et al. Forerunner genes contiguous to RB1 contribute to the development of in situ neoplasia. Proc Natl Acad Sci USA 2007;104:13732-13737.

45. Majewski T, Lee S, Jeong J, et al. Understanding the development of human bladder cancer by using a whole-organ genomic mapping strategy. Lab Invest [e-pub ahead of print: advance online publication 5 May 2008].

46. Jones S, Chen WD, Parmigiani G, et al. Comparative lesion sequencing provides insights into tumor evolution. Proc Natl Acad Sci USA 2008;105:4283-4288.

47. Chatelain D, Fléjou JF. High-grade dysplasia and superficial adenocarcinoma in Barrett's esophagus: histological mapping and expression of p53, p21 and Bcl-2 oncoproteins. Virchows Arch 2003;442:18-24.

48. Höglund M. Bladder cancer, a two phased disease? Semin Cancer Biol 2007; 17:225-232

49. Tomovska S, Richter J, Suess K, et al. Molecular cytogenetic alterations associated with rapid tumor cell proliferation in advanced urinary bladder cancer. Int J Oncol 2001;18:1239-1244.

50. Aaboe M, Birkenkamp-Demtroder K, Wiuf $C$, et al. SOX4 expression in bladder carcinoma: clinical aspects and in vitro functional characterization. Cancer Res 2006;66:3434-3442.

51. Schulz WA. Understanding urothelial carcinoma through cancer pathways. Int J Cancer 2006;119:1513-1518.

52. Hurst $C D$, Fiegler $H$, Carr $P$, et al. High-resolution analysis of genomic copy number alterations in bladder cancer by microarray-based comparative genomic hybridization. Oncogene 2004;23:2250-2263.

53. Leone $G$, Nuckolls $F$, Ishida $S$, et al. Identification of a novel E2F3 product suggests a mechanism for determining specificity of repression by Rb proteins. Mol Cell Biol 2000;20:3626-3632.

54. Humbert PO, Verona R, Trimarchi $J M$, et al. E2f3 is critical for normal cellular proliferation. Genes Dev 2000;14:690-703.

55. Lees JA, Saito M, Vidal M, et al. The retinoblastoma protein binds to a family of E2F transcription factors. Mol Cell Biol 1993;13:7813-7825.

56. Dimova DK, Dyson NJ. The E2F transcriptional network: old acquaintances with new faces. Oncogene 2005;24:2810-2826.

57. Oeggerli M, Schraml P, Ruiz C, et al. E2F3 is the main target gene of the $6 \mathrm{p} 22$ amplicon with high specificity for human bladder cancer. Oncogene 2006;25:6538-6543.

58. Olsson AY, Feber A, Edwards $\mathrm{S}$, et al. Role of E2F3 expression in modulating cellular proliferation rate in human bladder and prostate cancer cells. Oncogene 2007;26:1028-1037.

59. Hurst CD, Tomlinson DC, Williams SV, et al. Inactivation of the $\mathrm{Rb}$ pathway and overexpression of both isoforms of E2F3 are obligate events in bladder tumours with $6 \mathrm{p} 22$ amplification. Oncogene 2008;27:2716-2727.

60. Hellwinkel OJC, Kedia M, Isbarn $\mathrm{H}$, et al. Methylation of the TPEF- and PAX6-promoters is increased in early bladder cancer and in normal mucosa adjacent to pTa tumours. Brit J Urol Int 2007;101:753-757.

61. Eeles RA, Kote-Jarai Z, Giles GG, et al. Multiple newly identified loci associated with prostate cancer susceptibility. Nature Gen 2008;40:316-321.

62. Suzuki A, Shibata T, Shimada $Y$, et al. Identification of SMURF1 as a possible target for 7q21.3-22.1 amplification detected in a pancreatic cancer cell line by in-house array-based comparative genomic hybridization. Cancer Sci 2008;99:986-994.

63. Oldenburg RA, Meijers-Heijboer HM, Cornelisse CJ, et al. Genetic susceptibility for breast cancer: how many more genes to be found? Crit Rev Oncol/Hematol 2007;63:125-149.

64. Kallioniemi A. CGH microarrays and cancer. Curr Op Biotechnol 2008;19:36-40.

65. Thomas G, Jacobs KB, Yeager M, et al. Multiple loci identified in a genome-wide association study of prostate cancer. Nature Gen 2008:40:310-315.
66. Shann YJ, Cheng C, Chiao $\mathrm{CH}$, et al. Genome-wide mapping and characterization of hypomethylated sites in human tissues and breast cancer cell lines. Genome Res 2008; e-pub ahead of print. PMID 18256232.

67. Amos $\mathrm{Cl}, \mathrm{Wu} X$, Broderick $\mathrm{P}$, et al. Genome-wide association scan of tag SNPs identifies a susceptibility locus for lung cancer at 15q25.1. Nature Gen 2008;40:616-622

68. Monzon FA, Hagenkord JM, Lyons-Weiler MA, et al. Whole genome SNP arrays as a potential diagnostic tool for the detection of characteristic chromosomal aberrations in renal epithelial tumors. Mod Pathol 2008;21:599-608.

69. Baffa R, Letko J, McClung $C$, et al. Molecular genetics of bladder cancer: targets for diagnosis and therapy. J Exp Clin Cancer Res 2006:25:145-160.

70. Alvarez A, Lokeshwar VB. Bladder cancer biomarkers: current developments and future implementation. Curr Opin Urol 2007; 17:341-346.

71. Steiner H, Bergmeister M, Verdorfer I, et al. Early results of bladdercancer screening in a high-risk population of heavy smokers. Brit J Urol International epub ahead of print. PMID 18336612.

72. Frigerio S, Padberg BC, Strebel RT, et al. Improved detection of bladder carcinoma cells in voided urine by standardized microsatellite status. Int J Cancer 2007;121:329-338.

73. Szarvas T, Kovalszky I, Bedi K, et al. Deletion analysis of tumor and urinary DNA to detect bladder cancer: urine supernatant versus urine sediment. Oncol Rep 2007;18:405-409.

74. Bartoletti R, Dal Canto M, Cai T, et al. Early diagnosis and monitoring of superficial transitional cell carcinoma by microsatellite analysis on urine sediment. Oncol Rep 2005;13:531-537.

75. Wakui M, Shiigai T. Urinary tract cancer screening through analysis of urinary red blood cell volume distribution. Int J Urol 2000;7: 248-253.

76. Messing EM, Madeb R, Young T, et al. Long-term outcome of hematuria home screening for bladder cancer in men. Cancer 2006;107:2173-2179.

77. Messing EM, Young TB, Hung VB, et al. Comparison of bladder cancer outcome in men undergoing hematuria home screening versus those with standard clinical presentations. Urology 1995;45:387-396.

78. Marcus PM, Hayes RB, Vineis $\mathrm{P}$, et al. Cigarette smoking, $\mathrm{N}$ acetyltransferase 2 acetylation status, and bladder cancer risk: a caseseries meta-analysis of a gene-environment interaction. Cancer Epidemiol Biomarkers Prev 2000;9:461-467.

79. Miyakawa M, Tachibana M, Miyakawa A, et al. Re-evaluation of the latent period of bladder cancer in dyestuff-plant workers in Japan. Int J Urol 2001;8:423-430.

80. Lamm DL, Riggs DR, Shriver JS, et al. Megadose vitamins in bladder cancer: a double-blind clinical trial. J Urol 1994;151:21-26.

81. Prout Jr GR, Barton BA. 13-cis-retinoic acid in chemoprevention of superficial bladder cancer. The National Bladder Cancer Group. J Cell Biochem Suppl 1992;16I:148-152.

82. Decensi $A$, Bruno $S$, Costantini $M$, et al. Phase lla study of fenretinide in superficial bladder cancer, using DNA flow cytometry as an intermediate end point. J Natl Cancer Inst 1994;86:138-140.

83. Bruno $S$, Torrisi $R$, Costantini $M$, et al. Assessment of DNA flow cytometry as a surrogate end point biomarker in a bladder cancer chemoprevention trial. J Cell Biochem 1999;76:311-321.

84. Studer UE, Jenzer S, Biedermann C, et al. Adjuvant treatment with a vitamin $A$ analogue (etretinate) after transurethral resection of superficial bladder tumors. Final analysis of a prospective, randomized multicenter trial in Switzerland. Eur Urol 1995;28:284-290.

85. Sabichi AL, Lerner SP, Atkinson EN, et al. Phase III prevention trial of fenretinide in patients with resected non muscle-invasive bladder cancer. Clin Cancer Res 2008;14:224-229.

86. Messing E, Kim K, Sharkey F, et al. Randomized prospective phase III trial of difluoromethylornithine vs placebo in preventing recurrence of completely resected low risk superficial bladder cancer. J Urol 2006;176:500-504.

87. Grossman HB. Chemoprevention of bladder cancer. Urology 2006;67:19-22 